\title{
Evaluation of Central Nervous System Acting Effects of Plant-Derived Essential Oils Using Ambulatory Activity in Mice $^{*}$
}

\section{Toyoshi Umezu}

Biological Imaging and Analysis Section, Center for Environmental Measurement and Analysis, National Institute for Environmental Studies, Ibaraki, Japan.

Email: umechan2@nies.go.jp

Received January $18^{\text {th }}, 2013$; revised February $24^{\text {th }}, 2013$; accepted March $31^{\text {st }}, 2013$

Copyright (C) 2013 Toyoshi Umezu. This is an open access article distributed under the Creative Commons Attribution License, which permits unrestricted use, distribution, and reproduction in any medium, provided the original work is properly cited.

\begin{abstract}
Although plant-derived essential oils (EOs) have traditionally been used for treating various kinds of mental disorders, their Central Nervous System (CNS) acting effects have not yet been clarified well. The present study examined effects of 30 kinds of EOs on ambulatory activity, a kind of spontaneous motor activity, in ICR mice. Nineteen kinds of them did not produce any significant effects on the ambulatory activity of mice. Although effects of EOs of lavender, jasmine and neroli on the activity were statistically significant, their CNS acting properties remained unclear. EOs of peppermint, chamomile, thyme, tea tree, rosemary and basil significantly increased the ambulatory activity of mice as well as CNS stimulants, suggesting that they possess CNS stimulant-like effects. In contrast, an EO of myrtle significantly decreased the activity as well as CNS depressants, suggesting that it possesses a CNS depressant-like effect. An EO of palmarosa significantly increased the activity at a lower dose and decreased at a higher dose as well as some kinds of CNS depressants such as ethanol, suggesting that it also possesses a CNS depressant-like effect. These 8 kinds of EOs might be useful for treating some kinds of mental troubles and/or symptoms through their CNS acting effects.
\end{abstract}

Keywords: Essential Oil; Pharmacology; Psychoactive Effect; Behavior; Locomotion; Mouse

\section{Introduction}

Various plant-derived essential oils (EOs) have been used in European, Arabic, and Mediterranean countries for the treatment of different illnesses. The medicinal use of EOs began in ancient Egypt and has been practiced ever since. An opinion, in which EOs are effective for the treatment of mental illnesses, has been insisted, however, many scientists had doubted the efficacy of EOs because of the absence of a scientific basis for any claims [1,2].

One possible explanation for the efficacies of EOs on mental disorders is that EOs may possess Central Nervous System (CNS) acting effects as well as alreadyknown CNS acting drugs. Accumulating evidences [3], including those from our laboratory [4-11], indicate that some EOs produce pharmacological effects on animal behaviors similar to the effects of CNS acting drugs. However, these animal studies are limited and are still far

*This study was supported by the Smoking Research Foundation, Tokyo, Japan. way from fully supporting any efficacy clams associated with use of EOs for treating mental illnesses.

Current CNS acting drugs can be classified into two categories: CNS stimulants and CNS depressants. Many EOs are used for treating mental illnesses; however, it has not yet been known well whether different EOs produce a CNS stimulant-like effect, a CNS depressant-like effect, or neither of these effects. It has been reported that EOs of lavender [12,13], roman chamomile [14], neroli $[13,15]$, and sandalwood [13] might exhibit CNS depressant-like effects, whereas EOs of lemon [16], jasmine [17], rosemary [18], and sage [19] might exhibit CNS stimulant-like effects. However, these are only a small selection of EOs used, and their reliability has not been established.

One method for classifying CNS acting drugs into these categories involves assessing the conditioned avoidance response in animals [20-25]. The discrete shuttle-type task is one type of conditioned avoidance task. During this task, animals need to repeat shuttling in the experi- 
mental chamber to avoid an unconditioned stimulus, such as an electric shock, when a conditioned stimulus, such as a tone, is presented. Kuribara et al. [20] demonstrated that the discrete shuttle-type conditioned avoidance task in mice is useful for distinguishing CNS stimulants and CNS depressants; that is, CNS stimulants facilitate the avoidance response and CNS depressants suppress the avoidance response in mice performing this task. Using the discrete shuttle-type conditioned avoidance task in ddY mice, I have previously shown that EOs of peppermint and chamomile facilitate the avoidance response as well as CNS stimulants and that EOs of orange, cypress, grapefruit, eucalyptus and rose suppress the avoidance response as well as CNS depressants [26]. However, the results of some EOs in the study were disagree with the claims for their effects made by the previous studies [12, 13,15-17,19]. Therefore, further studies are necessary to clarify CNS acting properties of EOs.

Spontaneous motor activity of rodents is a fundamental behavioral indicator for classifying CNS acting drugs into CNS stimulants and CNS depressants; that is, CNS stimulants increase spontaneous motor activity and CNS depressants decrease the activity. Ambulatory activity, that can be measured using tilt-type ambulometer [27], is a kind of spontaneous motor activity of mice and is useful for evaluating pharmacological effects of CNS acting drugs [27-35]. Thus, it was expected that the ambulatory activity of mice would be useful for further examining whether specific EO produces CNS stimulant-like or CNS depressant-like effects or neither.

The present study examined effects of various CNS acting drugs on the ambulatory activity in ICR strain male mice to confirm the reliability of the activity as a behavioral indicator for distinguishing CNS stimulants and CNS depressants, followed by examining effects of 30 kinds of EOs on the activity under the same experimental condition. Results obtained in this study were compared with those in the previous study [26] to characterize their possible effects on CNS.

\section{Materials and Methods}

\subsection{Animals}

Male ICR strain mice (Clea Japan, Tokyo, Japan) aged 7 - 10 weeks and weighing between 35 - 42 g were housed in aluminum cages ( 3 mice/cage) with a stainless-steel mesh top and paper bedding. Commercial solid food (Clea Japan) and tap water were provided ad libitum. The cages were placed in a room artificially illuminated by fluorescent lamps on a 12L:12D schedule (light period: 07:00-19:00), at a room temperature of $25^{\circ} \mathrm{C} \pm 1^{\circ} \mathrm{C}$.

All experiments proceeded in accordance with the guidelines of the Ethics Committee for Experimental Animals of the National Institute for Environmental Studies, Ja- pan.

\subsection{Test Substances}

This study used various CNS acting drugs including CNS stimulants such as bupropion (BUP) (Sigma-Aldrich, Tokyo, Japan), caffeine (CAF) (Wako Pure Chem., Osaka, Japan), methylphenidate (MP) $\left(\right.$ Ritalin $^{\circledR}$, Japan CibaGeigy, Hyogo, Japan), phenethylamine (PHENE) and scopolamine (SCP) (Sigma-Aldrich), and CNS depressants such as diazepam (DZ) (Cercine Inj. ${ }^{\circledR}$, Takeda Chem. Ind., Osaka), haloperidol (HAL), fluphenazine (FLU) and spiperone (SPI) (Sima-Aldrich, Tokyo, Japan). DZ was diluted by $10 \%$ propylene glycol (Wako Pure Chem.) solution (10\% PG). HAL was dissolved in $0.1 \%$ acetic acid (Nacalai Tesque, Kyoto, Japan). Other drugs were dissolved in $0.9 \% \mathrm{NaCl}$ (Nacali Tesque) solution (saline).

EOs examined in the current study were peppermint (Menta piperita) (MINT), chamomile (Anthemis nobilis) (CHA), thyme (Thymus zygis) (THY), tea tree (Melaleuca alternifolia) (TEA), rosemary (Rosmarinus officinalis) (RSM), basil (Ocimum basilicum) (BAS), lavender (Lavandula angustifolia) (LAV), myrtle (Myrtus communis) (MYR), jasmine (Jasminum grandiflorum) (JAS), palmarosa (Cymbopogon martinii) (PAL), neroli (Citrus aurantium) (NER), lemon (Citrus limonum) (LMN), frankincense (Boswellia carterii) (FRA), geranium (Pelargonium graveolens) (GER), patchouli (Pogostemon cablin) (PAT), niaouli (Melaleuca quinquenervia) (NIA), vetiver (Vetiveria zizanoides) (VET), ravensara (Ravensara aromatica) (RAV), bergamot (Citrus bergamia) (BER), marjoram (Thymus mastichina) (MAR), rosewood (Aniba rosaedora var amazonica) (RSW), lemongrass (Cymbopogon citratus) (LMG), sandalwood (Santalum album) (SAN), cardamon (Elettaria cardamomum) (CAR), coriander (Coriandrum sativum) (COR), orange (Citrus sinensis) (ORA), cypress (Cupressus sempervirens) (CYP), grapefruit (Citrus paradisi) (GRAP), eucalyptus (Eucalyptus globulus) (EUC) and rose (Rosa damascena) (ROS). SAN, CAR and COR were produced by ROBERTTISSERAND Aromatherapy Product Ltd. (Brighton, UK) and other EOs were produced by Maggie Tisserand Ltd. (Brighton, UK). MINT, CHA, THY, TEA, RSM, BAS, LAV, MYR, PAL, NER, FRA, GER, PAT, NIA, VET, RAV, MAR, RSW, LMG, SAN, CAR, COR, CYP and EUC were produced using steam distillation method. LMN, BER, ORA and GRAP were produced using expression method. JAS and ROS were produced using solvent extraction method. All EOs were diluted with olive oil (Nakalai Tesque).

CNS acting drugs were subcutaneously administered to mice, and EOs was administered intraperitoneally. The administration volume was $1 \mathrm{ml} / 100 \mathrm{~g}$ body weight regardless of kinds of substances and dosage. 


\subsection{Measurement of Ambulatory Activity in ICR Mice}

Ambulatory activity, which is a type of spontaneous motor activity in mice, was measured using a tilt-type ambulometer consisting of 10 bucket-like Plexiglas activity cages (20 cm in diameter) (SAM-10; O'Hara and Co., Tokyo, Japan) [6-9,36-38]. Each activity cage is sustained by a fulcrum in the center of the bottom of the cage; the fulcrum tilts according to horizontal movement of the mouse in the activity cage. The tilting-movement of the activity cage activates micro-switches that surround the cage. The number of activations of microswitches during a set time is recorded, and result is printed out.

\subsection{Experimental Procedures}

\subsubsection{Effects of CNS Acting Drugs on Ambulatory Activity in Mice}

Mice were placed individually in activity cages, and after 30 min of adaptation, vehicle or each dose of each CNS acting drug was administered subcutaneously. Thereafter, ambulatory activity was continuously measured for 60 $\min$.

\subsubsection{Effects of EOs on Ambulatory Activity in Mice} Mice were placed individually in activity cages, and after 30 min of adaptation, olive oil or each dose of each EO was administered intraperitoneally. Thereafter, ambulatory activity was continuously measured for $60 \mathrm{~min}$.

\subsection{Statistical Analysis}

To eliminate differences of baseline ambulatory activity, the activity of each animal after administration of each substance was normalized using the total activity of the animal during the $30 \mathrm{~min}$ adaptation period before administration of each substances [37].

Differences in total normalized ambulatory activity over 60 min were analyzed using one-way analysis of variance (ANOVA), followed by Dunnett test. $\mathrm{P}<0.05$ was established as the level of significance.

\section{Results}

\subsection{Effects of CNS Acting Drugs on Ambulatory Activity in Mice}

All CNS stimulants such as BUP $(\mathrm{F}(2,217)=51.615, \mathrm{P}$ $<0.05), \operatorname{CAF}(\mathrm{F}(3,76)=6.726, \mathrm{P}<0.05), \mathrm{MP}(\mathrm{F}(2,317)$ $=96.949, \mathrm{P}<0.05)$, PHENE $(\mathrm{F}(3,176)=25.886, \mathrm{P}<$ $0.05)$ and $\operatorname{SCP}(F(3,76)=32.525, \mathrm{P}<0.05)$ significantly increased the ambulatory activity in ICR mice (Figure 1). On contrary, all CNS depressants such as DZ $(F(3,76)=$ 3.111, $\mathrm{P}<0.05)$, HAL $(\mathrm{F}(3,68)=7.588, \mathrm{P}<0.05)$, FLU $(\mathrm{F}(3,64)=2.907, \mathrm{P}<0.05)$ and $\mathrm{SPI}(\mathrm{F}(3,68)=5.64, \mathrm{P}<$ $0.05)$ significantly decreased the ambulatory activity in mice (Figure 2).

\subsection{Effects of EOs on Ambulatory Activity in Mice}

MINT and CHA significantly increased the ambulatory

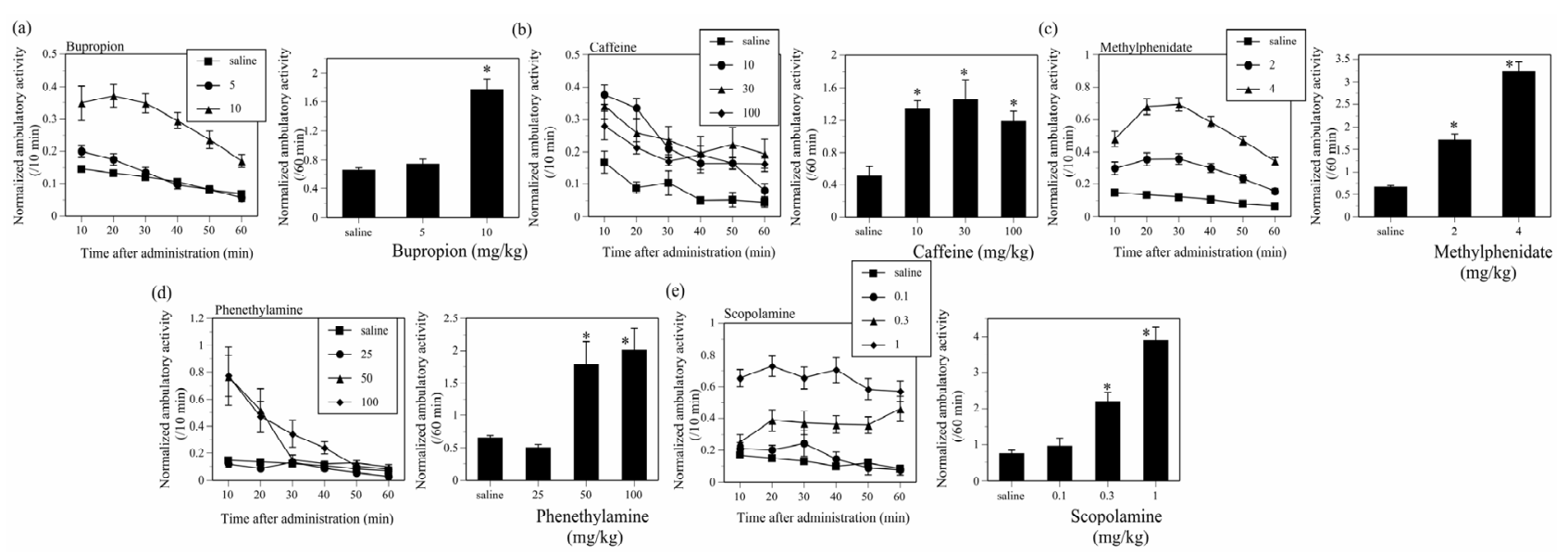

Figure 1. Effects of CNS stimulants such as BUP (a), CAF (b), MP (c), PHENE (d) and SCP (e) on the ambulatory activity in ICR mice. The figures show normalized ambulatory activity that was obtained normalizing the actual ambulatory measurement using total ambulatory activity during the $\mathbf{3 0}$ min adaptation period before administration to each mouse. Left panels; Changes in the normalized ambulatory activity in mice after administration. Symbols show mean values of normalized ambulatory activity for each 10-min period, and vertical lines denote standard errors of the mean (S.E.M.). Right panels; Total normalized ambulatory activity for 60 minutes after administrations of test substances or its vehicle. Filled columns show mean values of total ambulatory activity for 60 minutes, and vertical lines indicate S.E.M. Total normalized ambulatory activity for 60 minutes was analyzed by one-way ANOVA, followed by Dunnett test. ${ }^{*} \mathrm{P}<0.05$ compared with control value obtained after vehicle administration. $N=40-120$ animals per dose group for $B U P, N=20$ for CAF, $N=100-120$ for $M P, N=$ 20 - 120 for PHENE, $\mathbf{N}=20$ for SCP. 
(a)

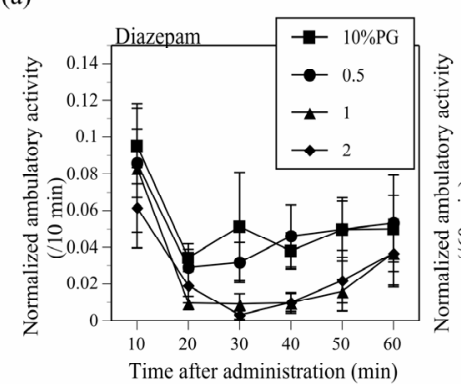

(c)

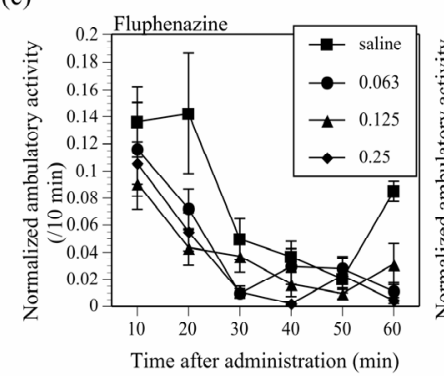

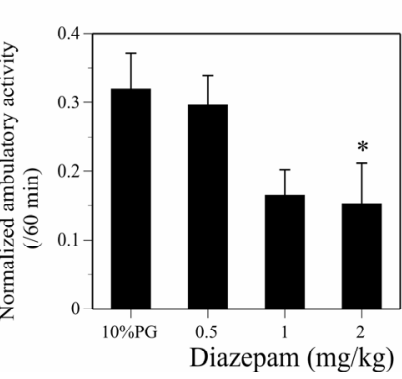

Diazepam $(\mathrm{mg} / \mathrm{kg})$

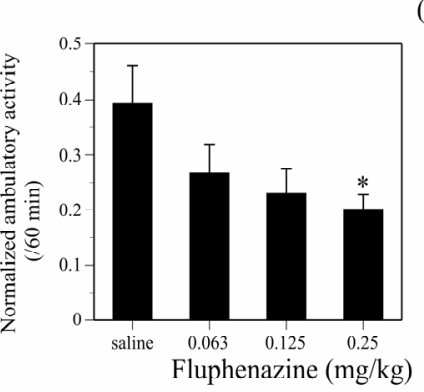

(b)
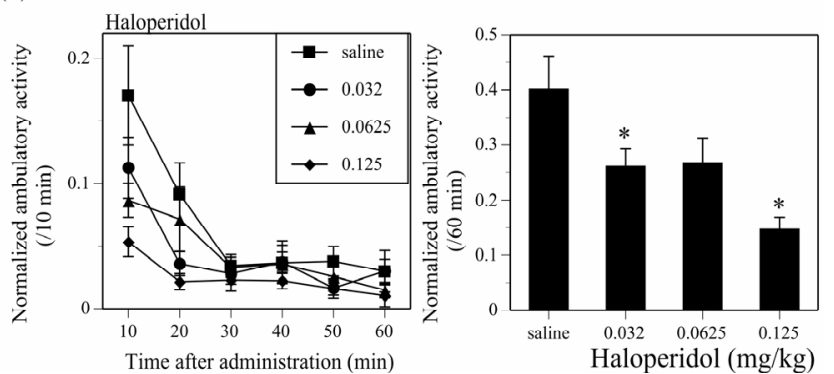

(d)

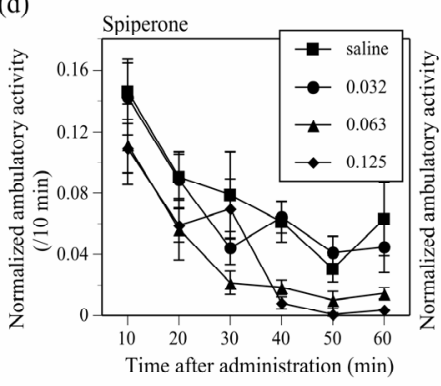

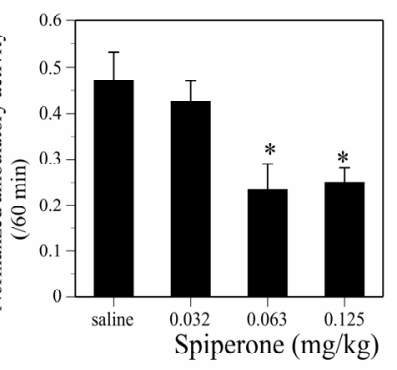

Figure 2. Effects of CNS depressants such as DZ (a), HAL (b), FLU (c) and SPI (d) on the ambulatory activity in ICR mice. N $=20$ for DZ, $N=18$ - 19 for HAL, $N=16-18$ for FLU, $N=18$ for SPI.

activity of mice $(\mathrm{MINT} ; \mathrm{F}(4,135)=15.49, \mathrm{P}<0.05$, CHA; F(6, 173) = 23.39, P < 0.05) (Figure 3). Similarly, THY, TEA, RSM, BAS and LAV also significantly increased the ambulatory activity in mice (THY, F(4, 135) $=16.579, \mathrm{P}<0.05$; TEA, F(4, 134) = 10.794, $\mathrm{P}<0.05$; RSM, F(4, 135) = 6.266, $\mathrm{P}<0.05$; BAS, $\mathrm{F}(4,134)=$ 3.954, $\mathrm{P}<0.05$; LAV, F(4, 135) = 4.677, $\mathrm{P}<0.05)$ (Figure 4).

MYR $(F(4,135)=4.746, \mathrm{P}<0.05)$ significantly decreased the ambulatory activity in mice (Figure 5(a)). JAS $(F(4,135)=2.584, \mathrm{P}<0.05)$ significantly decreased the activity, however, the effect was not dose-dependent (Figure 5(b)). PAL significantly increased the ambulatory activity at a lower dose and decreased at a higher dose $(\mathrm{F}(4,135)=9.148, \mathrm{P}<0.05)($ Figure 5(c)) .

ANOVA indicated the effect of NER was significant $(\mathrm{F}(4,135)=2.537, \mathrm{P}<0.05)$, however, Dunnett test did not indicate statistical significance on the effect (Figure 6(a)). LMN $(\mathrm{F}(4,134)=2.015)$, FRA $(F(4,135)=1.964)$, GER $(F(4,135)=1.505)$, PAT $(F(4,135)=2.154)$, NIA $(\mathrm{F}(4,135)=0.983), \operatorname{VET}(\mathrm{F}(4,135)=1.445), \mathrm{RAV}(\mathrm{F}(4$, $135)=0.804), \operatorname{BER}(F(4,135)=1.091), \operatorname{MAR}(F(4,135)$ $=0.207)$, RSW $(F(4,133)=2.34), \operatorname{LMG}(F(4,134)=$ 3.226), SAN $(\mathrm{F}(4,135)=0.831)$, CAR $(\mathrm{F}(4,135)=$ 0.992), $\mathrm{COR}(\mathrm{F}(4,135)=1.298)$, ORA $(\mathrm{F}(4,135)=$ 2.508), $\operatorname{CYP}(\mathrm{F}(4,134)=0.629)$, $\operatorname{GRAP}(\mathrm{F}(4,135)=$ $0.288)$, EUC $(F(4,134)=1.533)$ and $\operatorname{ROS}(F(4,129)=$ 0.178 ) did not produce any significant effects on the ambulatory activity in mice (all essential oils, $\mathrm{P}>0.05$ ) (Figures 6-8).

\section{Discussion}

The present study confirmed the usefulness of the ambulatory activity in ICR mice for distinguishing CNS acting drugs into CNS stimulants and CNS depressants. The BUP, CAF, MP, PHENE and SCP drugs, all of which are CNS stimulants $[8,27,33,38-44]$ increased the ambulatory activity in ICR mice, and DZ, HAL, FLU and SPI, all of which are CNS depressants [6-8,20,23-26,38,45-48], decreased the activity. These results show that the ambulatory activity in ICR male mice is useful for determining whether specific EOs exhibit CNS stimulant-like or CNS depressant-like effects or neither. The present study examined effects of totally 30 kinds of EOs on the ambulatory activity in ICR mice under the same condition for evaluating effects of CNS acting drugs. Table 1 summarized the effects of them on the ambulatory activity in mice, and they were compared with the effects on the discrete shuttle-type conditioned avoidance response in mice [26].

Since LMN, FRA, GER, PAT, NIA and VET did not produce any effects on either the ambulatory activity or the discrete avoidance response in mice (Table 1), it is highly probable that these EOs do not possess either CNS stimulant-like or CNS depressant-like effects. In addition, it is also probable that RAV, BER, MAJ, RSW, LMG, SAN, CAR and COR do not possess either CNS stimulant-like or CNS depressant-like effects, given that they did not produce any significant effects on the ambulatory activity.

ORA, CYP, GRAP, EUC and ROS produced no ef- 
(a)
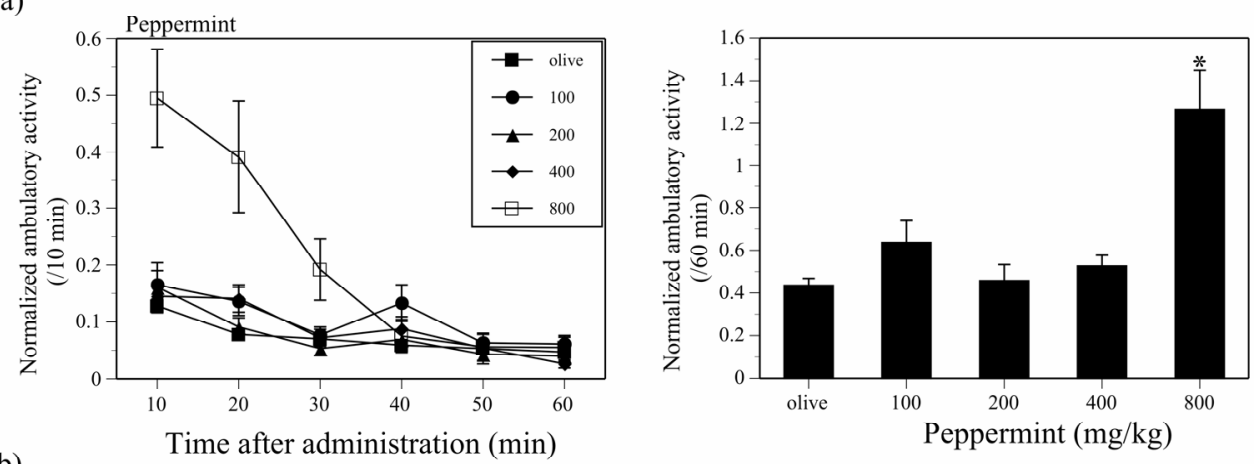

(b)
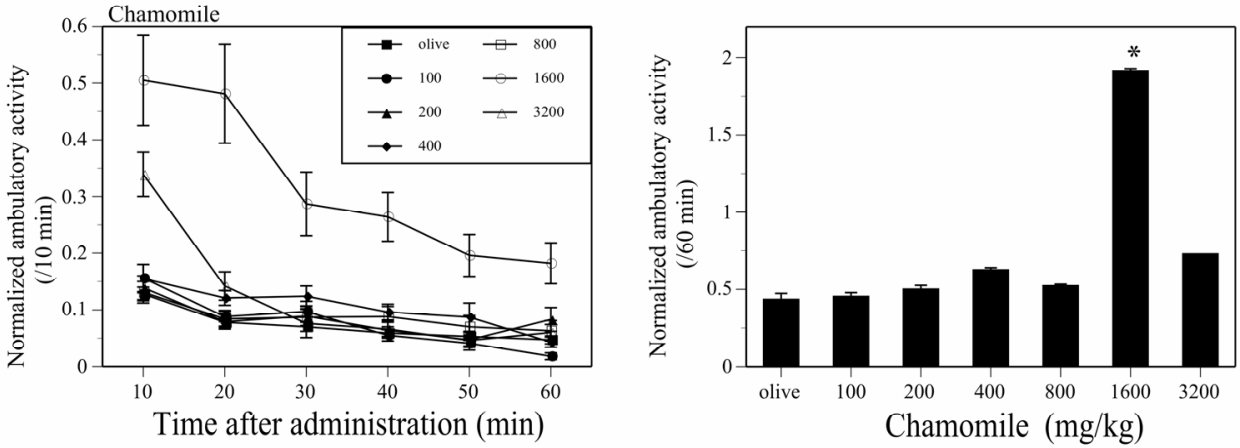

Figure 3. Effects of MINT (a) and CHA (b) on the ambulatory activity in ICR mice. $N=20-60$ for MINT, $N=20-60$ for CHA.

(a)
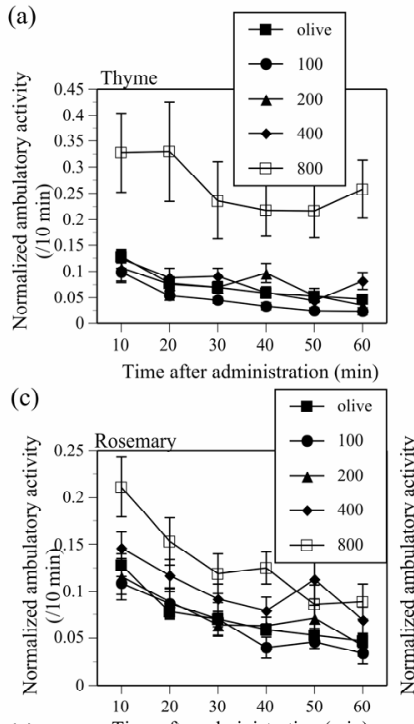

(e) Timc aftcr administration ( $\mathrm{min})$

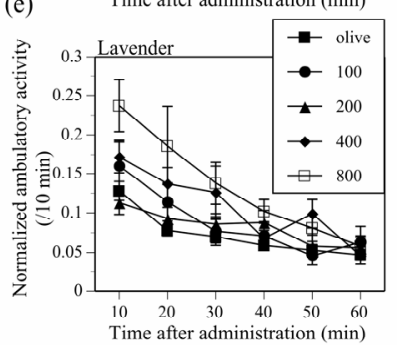

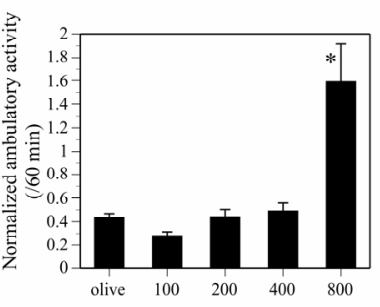

Thyme ( $\mathrm{mg} / \mathrm{kg})$

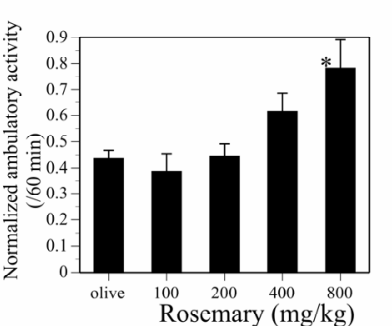

Roscmary $(\mathrm{mg} / \mathrm{kg})$

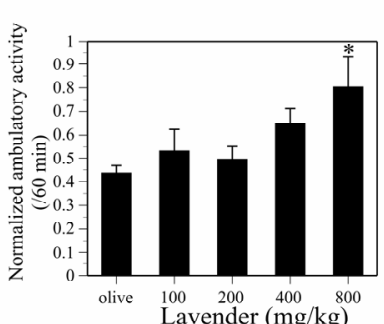

(b)
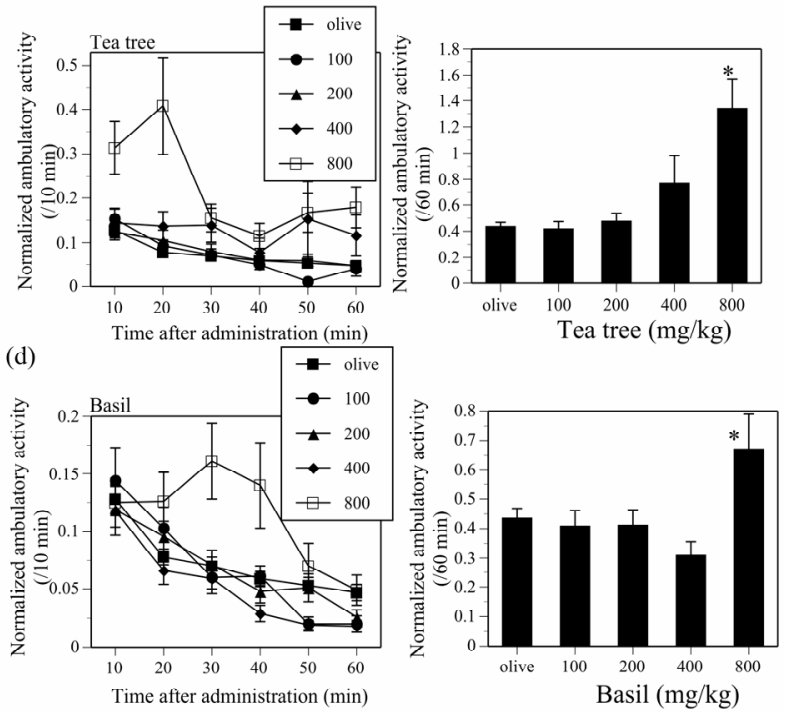

Figure 4. Effects of THY (a), TEA (b), RSM (c), BAS (d) and LAV (e) on the ambulatory activity in ICR mice. THY, N = 20 60, TEA, $N=19-60$, RSM, $N=20-60$, BAS, $N=20-60$, LAV, $N=20-60$. 

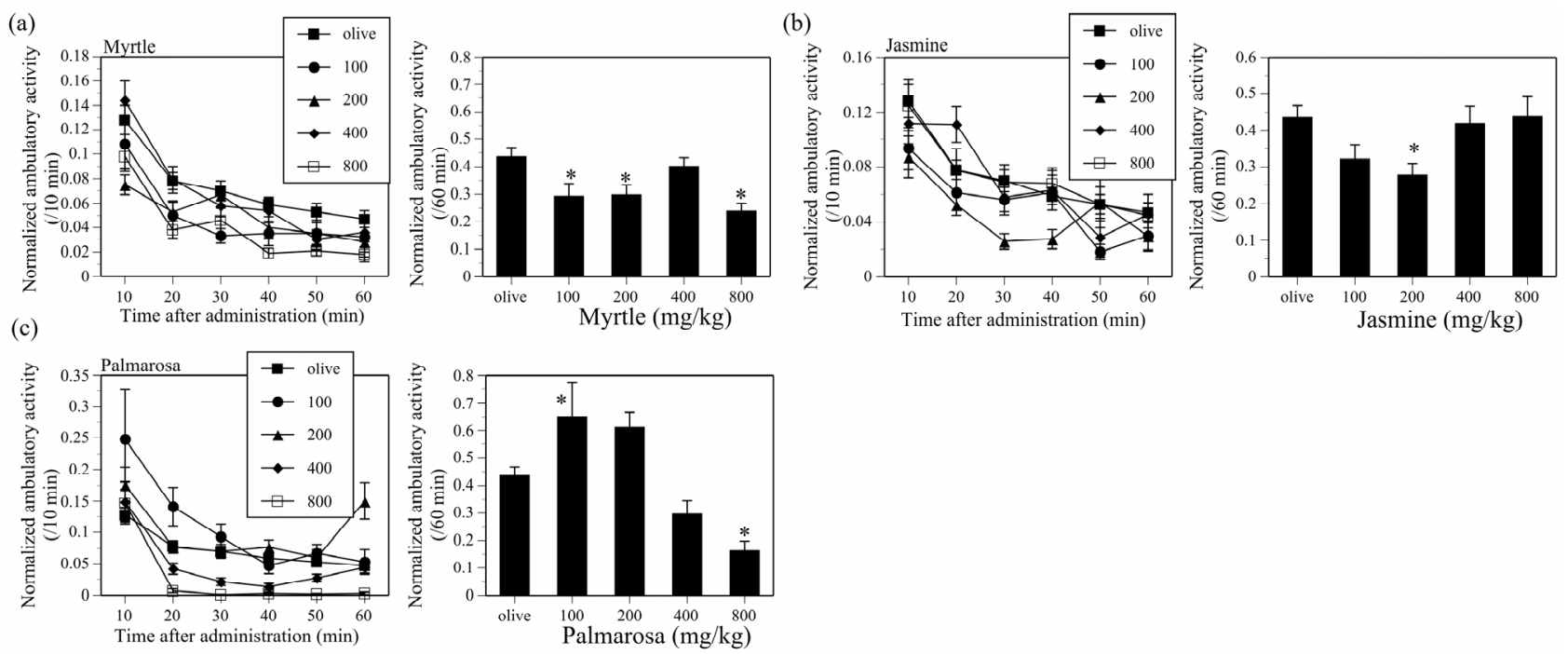

Figure 5. Effects of MYR (a), JAS (b) and PAL (c) on the ambulatory activity in ICR mice. MYR, N = 20 - 60, JAS, N = 20 60, PAL, $N=20-60$.

fects on the ambulatory activity although these EOs suppress the avoidance response (Table 1). The behavioral effects of these EOs are different from those of CNS depressants (Table 1). More precisely, ORA and CYP decrease the response rate of the avoidance response, EUC and ROS decrease the avoidance rate of the avoidance response, and GRAP decrease both the response rate and avoidance rate [26]. The response rate of the discrete shuttle-type conditioned avoidance response is the number of shuttling (horizontal movement) of mouse in the experimental chamber per minute, therefore, change of the response rate indicates change of motor activity under the conditioned avoidance situation. ORA significantly suppresses the response rate at only a middle dose and the effect is not dose-dependent, and did not decrease the ambulatory activity. Therefore, it is hard to say that ORA consistently suppresses motor activity in mice. CYP significantly decreases the response rate at the 2nd highest dose and tended to decrease the ambulatory activity at the highest dose. GRPA significantly decreases the response rate at the two highest doses and produced no effects on the ambulatory activity at any doses. Thus, effects of CYP and GRPA on motor activities would be very weak if they suppressed motor activities of mice. EUC and ROS decrease the avoidance rate without affecting the response rate and did not produce any effects on the ambulatory activity, showing that these EOs do not suppress motor activities of mice. In conclusion, CNS depressant-like effects of ORA, CYP, GRAP, EUC and ROS are not obvious although they may have some CNS acting effects.

NER tended to increase the ambulatory activity. ANOVA indicated that the effect of NER was significant, however, the effect was not statistically significant when compared between vehicle treated control group and each dose group. Since reliability of the NER effect is unclear, further studies will be needed to clarify this issue.

In contrast, other 10 kind of EOs produced statistically significant effects on the ambulatory activity of mice in this study. MINT, CHA, THY, TEA, RSM, BAS, and LAV significantly increased the ambulatory activity, and MYR and JAS significantly decreased the ambulatory activity. PAL significantly increased the activity at a lower dose and significantly decreased at a higher dose.

MINT increased the ambulatory activity of mice in this study as previously reported [9] and facilitates the avoidance response in mice (Table 1). Similarly, CHA also increased the ambulatory activity and facilitates the avoidance response (Table 1). Since these behavioral effects of MINT and CHA are as same as those of CNS stimulants (Table 1), they probably possess CNS stimulant-like effects.

The present study revealed that THY, TEA, RSM, BAS and LAV increased the ambulatory activity in mice. As a previous study [18] also reported that rosemary essential oil increases locomotor activity of mice after inhalation or oral administration, effects of RSM on spontaneous motor activity in mice seem reliable. RSM probably possesses a CNS simulant-like effect. To my knowledge, this is the first report on the ambulation-increasing effects of THY, TEA and BAS. They may also possess CNS stimulant-like effects. The effect of LAV is unexpected, as it has traditionally been believed to produce sedation in human. Previous animal studies also show that inhalation of vapor of lavender essential oil decreases the motility of mice [12,13]. On the other hand, LAV does not produce any significant effects on the avoidance response (Table 1). Thus, LAV used in my 
(a)

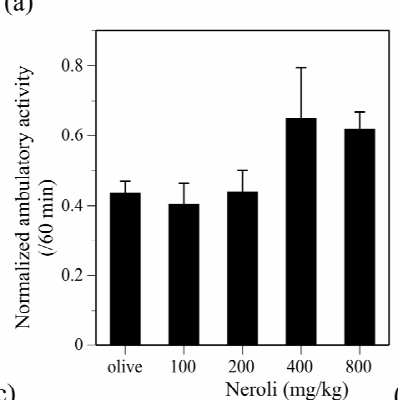

(c)

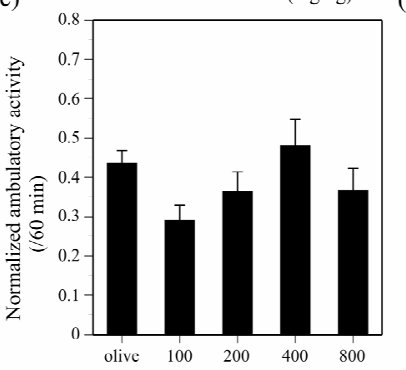

(e)

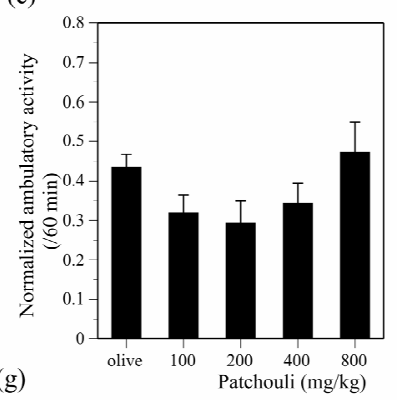

(g)

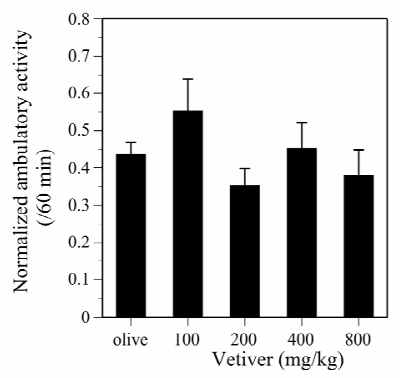

Figure 6. Effects of NER (a), LMN (b), FRA (c), GER (d), PAT (e), NIA (f) and VET (g) on the ambulatory activity in ICR mice. NER, N = 20 - 60, LMN, N = 19 - 60, FRA, N = 20 - 60, GER, $N=20$ - 60, PAT, $N=20$ - 60, NIA, $N=20$ - 60, VET, $N=20-60$.

previous and present studies does not decrease motor activities of mice after intraperitoneal administration. It is probable that LAV does not possess a CNS depressant-like effect, however, whether LAV possesses a CNS stimulant-like effect or not is still a matter for argument.

JAS significantly decreased the ambulatory activity at a middle dose but the effect was not dose-dependent. In addition, no effect is observed on the avoidance response (Table 1). Thus, it is hard to say that JAS consistently suppress motor activities in mice. Although JAS might
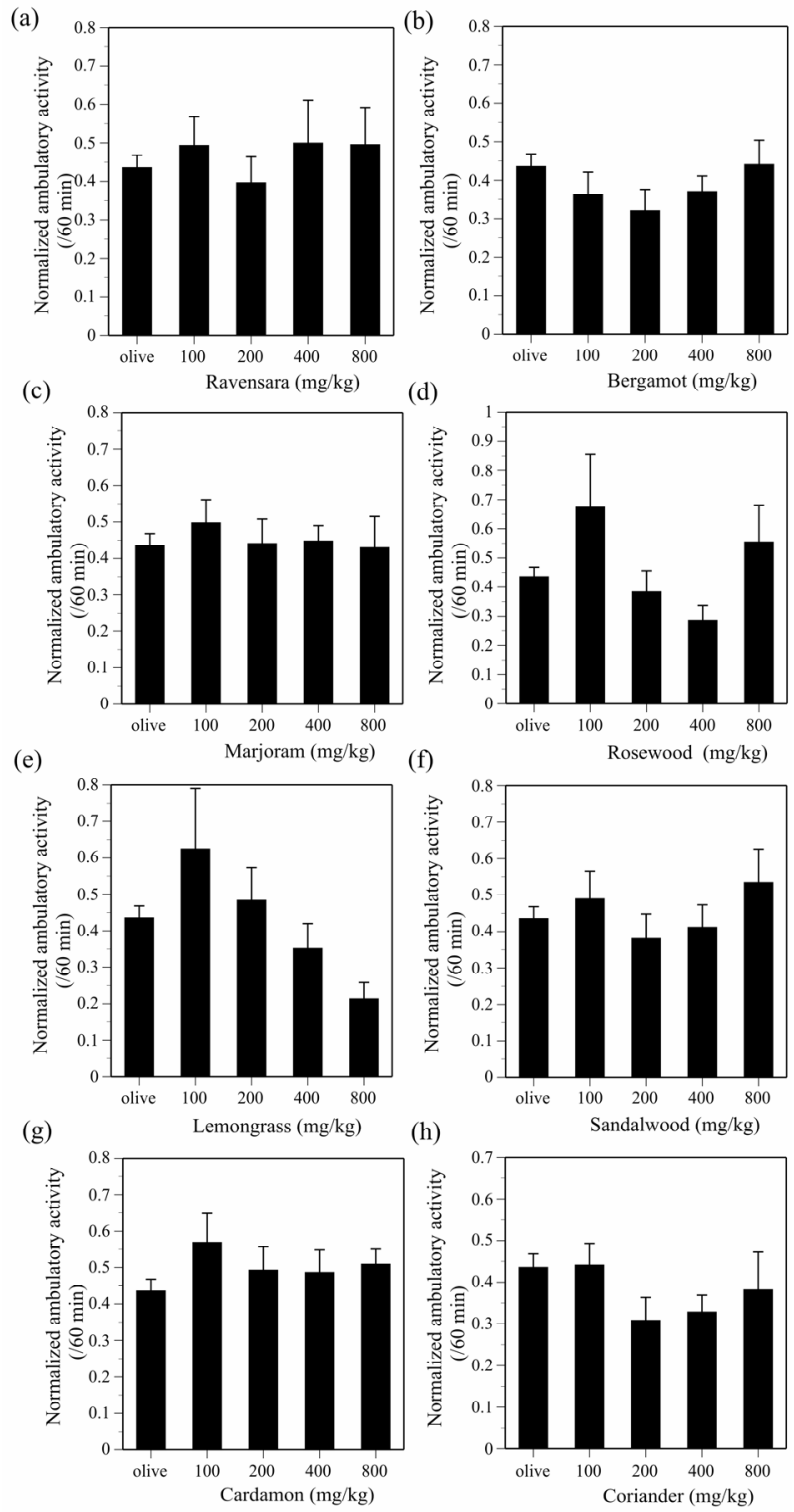

Figure 7. Effects of RAV (a), BER (b), MAR (c), RSW (d), LMG (e), SAN (f), CAR (g) and COR (h) on the ambulatory activity in ICR mice. RAV, $N=20-60, B E R, N=20-60$, MAR, $\mathbf{N}=20-60$, RSW, $N=19-60$, LMG, $N=20-60$, SAN, $N=20$ - 60, CAR, $N=20-60$, COR, $N=20-60$.

possess some CNS acting effects, a CNS depressant-like effect of JAS is not obvious. In contrast, MYR consistently decreased the ambulatory activity at plural doses, suggesting that MYR possesses a CNS depressant-like effect. PAL increased the ambulatory activity at a lower dose but decreased the activity at a higher dose. This characteristic is different from those of CNS depressants examined in this study (Table 1). Ethanol, another kind of CNS depressants, is known to produce behavioral excitations. For example, adequate doses of ethanol increase the ambulatory activity in mice [49]. Such effects produced by some CNS depressants are known as “disin- 

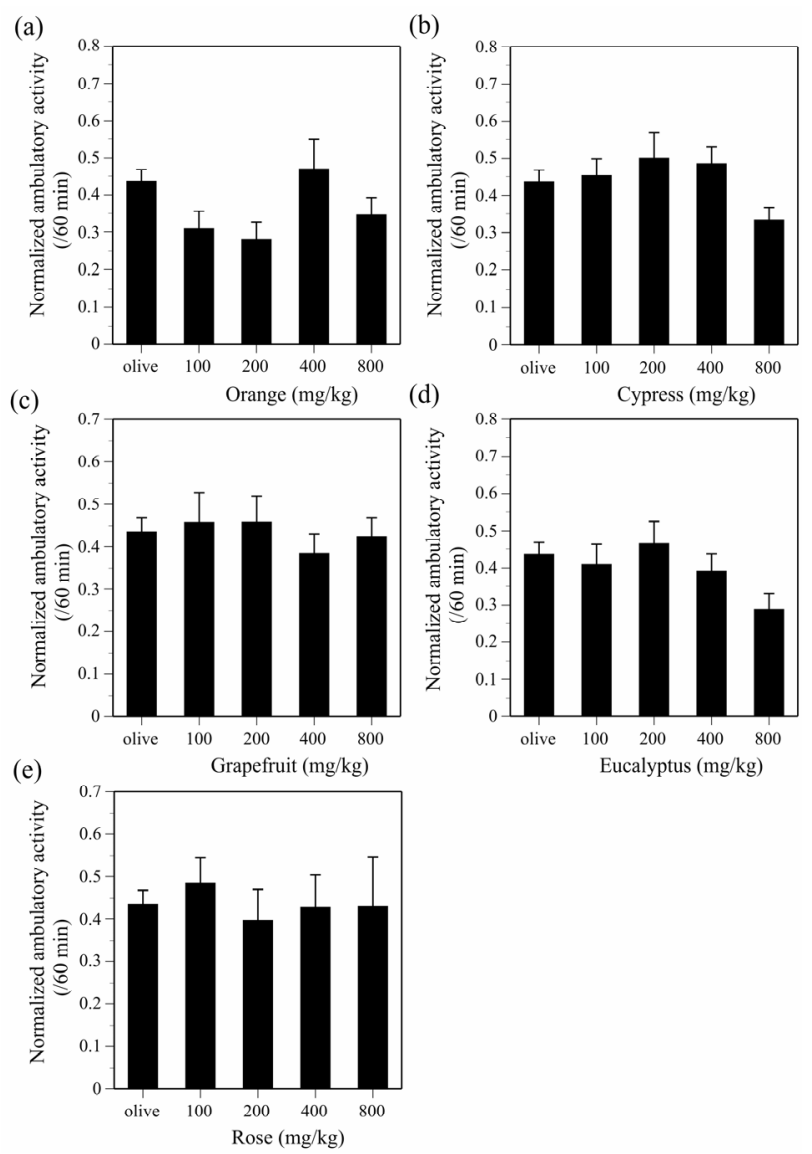

Figure 8. Effects of ORA (a), CYP (b), GRAP (c), EUC (d) and ROS (e) on the ambulatory activity in ICR mice. ORA, $\mathrm{N}=20$ - 60, CYP, $\mathrm{N}=19$ - 60, GRAP, $\mathrm{N}=20$ - 60, EUC, $\mathrm{N}=$ 20 - 60, ROS, N = 18 - 60 .

hibition phenomena", which are defined as behavioral excitations produced by drugs through inhibition of inhibitory mechanism(s) among CNS. PAL may possess a CNS effect similar to that of ethanol.

Other interesting findings in the present study are that DZ, a benzodiazepine anxiolytic, significantly decreased the ambulatory activity but ROS and LAV, both of which produce antianxiety-like effects in mice as well as DZ [4, $5,10,11,50]$, did not. The effects of ROS and LAV on the avoidance response are also different from that of DZ [26]. LAV and ROS might be valuable candidates for new kinds of anxiolytics that produce antianxiety effects without apparent behavioral suppression.

\section{Conclusion}

The present study revealed that 10 kinds of EOs produce statistically significant effects on the ambulatory activity in ICR mice as well as already-known CNS acting drugs. Among them, MINT, CHA, THY, TEA, RSM and BAS probably possess CNS stimulant-like effects and MYR and PAL probably possess CNS depressant-like effects.
Table 1. Effects of CNS acting drugs and plant-derived essential oils on the ambulatory activity in ICR mice and on the discrete shuttle-type conditioned avoidance response in ddY mice (ref. [26]).

\begin{tabular}{|c|c|c|}
\hline & Ambulation & Conditioned avoidance response \\
\hline \multicolumn{3}{|l|}{ CNS acting drug } \\
\hline \multicolumn{3}{|l|}{ CNS stimulant } \\
\hline Bupropion & $\widehat{\varphi}$ & \\
\hline Caffeine & 艺 & $\widehat{\varphi}$ \\
\hline Methylphenidate & 仓 & \\
\hline Phenethylamine & $\widehat{\varphi}$ & $\widehat{\varphi}$ \\
\hline Scopolamine & 仓 & 仓 \\
\hline Apomorphine & & 仓 \\
\hline MK-801 & & 仓 \\
\hline Cyclazocine & & 仓 \\
\hline \multicolumn{3}{|l|}{ CNS depressant } \\
\hline Diazepam & $\sqrt{3}$ & $\sqrt{3}$ \\
\hline Haloperidol & $\sqrt{3}$ & $\sqrt{3}$ \\
\hline Fluphenazine & $\sqrt{3}$ & \\
\hline Spiperone & $\sqrt{3}$ & \\
\hline Chlorpromazine & & $\Omega$ \\
\hline \multirow{2}{*}{ Physostigmine } & & $\sqrt{3}$ \\
\hline & Ambulation & Conditioned avoidance response \\
\hline \multicolumn{3}{|l|}{ Essential oil } \\
\hline Peppermint & 仓 & 仓 \\
\hline Chamomile & $\widehat{\imath}$ & $\widehat{v}$ \\
\hline Thyme & 凹 & \\
\hline Tea tree & 仓 & \\
\hline Rosemary & 仓 & \\
\hline Basil & 仓 & \\
\hline Lavender & $\widehat{\imath}$ & - \\
\hline Myrtle & $\sqrt{3}$ & \\
\hline Jasmine & $\sqrt{3}$ & - \\
\hline Palmarosa & 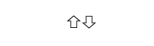 & \\
\hline Neroli & « (?) & - \\
\hline Lemon & - & - \\
\hline Frankincense & - & - \\
\hline Geranium & - & - \\
\hline Patchouli & - & - \\
\hline Niaouli & - & - \\
\hline Vetiver & - & - \\
\hline Ravensara & - & \\
\hline Bergamot & - & \\
\hline Majoram & - & \\
\hline Rosewood & - & \\
\hline Lemongrass & - & \\
\hline Sandalwood & - & \\
\hline Cardamon & - & \\
\hline Coriander & - & \\
\hline Orange & - & $\sqrt{3}$ \\
\hline Cypress & - & $\Omega$ \\
\hline Grapefruit & - & $\Omega$ \\
\hline Eucalyptus & - & $\sqrt{3}$ \\
\hline Rose & - & $\Omega$ \\
\hline Juniper & & - \\
\hline Clary sage & & - \\
\hline Ylang-ylang & & - \\
\hline Linden & & 仓 \\
\hline
\end{tabular}


These EOs may be useful for treating some kinds of mental troubles and/or symptoms through their CNS acting effects.

\section{REFERENCES}

[1] M. Lis-Balchin, “Essential Oils and 'Aromatherapy': Their Modern Role in Healing," Journal of the Royal Society of Health, Vol. 117, No. 5, 1997, pp. 324-329. doi:10.1177/146642409711700511

[2] J. Buckle, "Use of Aromatherapy as a Complementary Treatment of Chronic Pain," Alternative Therapies in Health and Medicine, Vol. 5, No. 5, 1999, pp. 42-51.

[3] N. Perry and E. Perry, "Aromatherapy in the Management of Psychiatric Disorders. Clinical and Neuropharmacological Perspectives,” CNS Drugs, Vol. 20, No. 4, 2006, pp. 257-280. doi:10.2165/00023210-200620040-00001

[4] T. Umezu, "Anticonflict Effects of Plant-Derived Essential Oil,” Pharmacology Biochemistry and Behavior, Vol. 64, No. 1, 1999, pp. 35-40. doi:10.1016/S0091-3057(99)00115-X

[5] T. Umezu, "Behavioral Effects of Plant-Derived Essential Oils in the Geller Type Conflict Test in Mice,” Japanese Journal of Pharmacology, Vol. 83, No. 2, 2000, pp. 150153. doi:10.1254/jip.83.150

[6] T. Umezu, "Evidence for Dopamine Involvement in Ambulation Promoted By Menthone in Mice,” Pharmacology Biochemistry and Behavior, Vol. 91, No. 3, 2009, pp. 315-320. doi:10.1016/j.pbb.2008.07.017

[7] T. Umezu, "Evidence for Dopamine Involvement in Ambulation Promoted by Pulegone in Mice,” Pharmacology Biochemistry and Behavior, Vol. 94, No. 4, 2010, pp. 497-502. doi:10.1016/j.pbb.2009.11.001

[8] T. Umezu and M. Morita, "Evidence for the Involvement of Dopamine in Ambulation Promoted by Menthol in Mice,” Journal of Pharmacological Sciences, Vol. 91, No. 2, 2003, pp. 125-135. doi:10.1254/jphs.91.125

[9] T. Umezu, A. Sakata and H. Ito, “Ambulation-Promoting Effect of Peppermint Oil and Identification of Its Active Constituents," Pharmacology Biochemistry and Behavior, Vol. 69, No. 3-4, 2001, pp. 383-390. doi:10.1016/S0091-3057(01)00543-3

[10] T. Umezu T, H. Ito, K. Nagano, M. Yamakoshi, H. Oouchi, M. Sakaniwa and M. Morita, "Anticonflict Effects of Rose Oil and Identification of Its Active Constituents,” Life Sciences, Vol. 72, No. 1, 2002, pp. 91-102. doi:10.1016/S0024-3205(02)02197-5

[11] T. Umezu, K. Nagano, H. Ito, K. Kosakai, M. Sakaniwa and M. Morita, "Anticonflict Effects of Lavender Oil and Identification of Its Active Constituents,” Pharmacology Biochemistry and Behavior, Vol. 85, No. 4, 2006, pp. 713-721. doi:10.1016/j.pbb.2006.10.026

[12] G. Buchbauer, L. Jirovetz and W. Jäger, “Aromatherapy: Evidence for Sedative Effects of the Essential Oil of Lavender after Inhalation," Zeitschrift fur Naturforschung C-A Journal of Biosciencesz, Vol. 46, No. 11-12, 1991, pp. 1967-1972.

[13] G. Buchbauer, L. Jirovetz, W. Jäger, C. Plank and H.
Dietrich, "Fragrance Compounds and Essential Oils with Sedative Effects upon Inhalation," Journal of Pharmaceutical Sciences, Vol. 82, No. 6, 1993, pp. 660-664. doi:10.1002/jps.2600820623

[14] T. Rossi, M. Melegari, A. Bianchi, A. Albasini and G. Vampa, "Sedative, Anti-Inflamatory and Anti-Diuretic Effects Induced in Rats by Essential Oils of Varieties of Anthemis nobilis: A Comparative Study," Pharmacological Research Communications, Vol. 20, Suppl. 5, 1988, pp. 71-74. doi:10.1016/S0031-6989(88)80844-0

[15] M. I. R. Carvalho-Freitas and M. Costa, “Anxiolytic and Sedative Effects of Extracts and Essential Oil from Citrus aurantium L.," Biological \& Pharmaceutical Bulletin, Vol. 25, No. 12, 2002, pp. 1629-1633. doi:10.1248/bpb.25.1629

[16] T. Komori, R. Fujiwara, M. Tanida and J. Nomura, "Potential Antidepressant Effects of Lemon Odor in Rats," European Neuropsychopharmacology, Vol. 5, No. 4, 1995, pp. 477-480. doi:10.1016/0924-977X(95)00020-P

[17] T. Tsuchiya, M. Tanida, S. Uenoyama and Y. Nakayama, "Effects of Olfactory Stimulation with Jasmine and Its Component Chemicals on the Duration of PentobarbitalInduced Sleep in Mice,” Life Sciences, Vol. 50, No. 15, 1992, pp. 1097-1102. doi:10.1016/0024-3205(92)90346-Q

[18] K. A. Kovar, B. Gropper, D. Friess and H. P. Ammon, "Bood Levels of 1,8-Cineol and Locomotor Activity of Mice after Inhalation and Oral Administration of Rosemary Oil,” Planta Medica, Vol. 53, No. 4, 1987, pp. 315318. doi:10.1055/s-2006-962725

[19] G. Wake, J. Court, A. Pickering, R. Lewis, R. Wilkins and E. Perry, "CNS Acetylcholine Receptor Activity in European Medicinal Plants Traditionally Used to Improve Failing Memory,” Journal of Ethnopharmacology, Vol. 69, No. 2, 2000, pp. 105-114. doi:10.1016/S0378-8741(99)00113-0

[20] H. Kuribara, H. Haraguchi and S. Tadokoro, "Comparisons between Discrete Lever-Press and Shuttle Avoidance Responses in Mice: Acquisition Processes and Psychoactive Drugs,” Japanese Journal of Pharmacology, Vol. 38, No. 2, 1985, pp. 141-51. doi:10.1254/jip.38.141

[21] H. Kuribara and S. Tadokoro, "Comparison of Susceptibilities to the Effect of Antipsychotic Drugs on LeverPress Avoidance Response between Mice and Rats," Japanese Journal of Pharmacology, Vol. 33, No. 6, 1983, pp. 1127-1133. doi:10.1254/jjp.33.1127

[22] H. Kuribara and S. Tadokoro, "Conditioned Lever-Press Avoidance Response in Mice: Acquisition Processes and Effects of Diazepam,” Psychopharmacology (Berlin), Vol. 82, No. 1-2, 1984, pp. 36-40. doi:10.1007/BF00426377

[23] H. Kuribara and S. Tadokoro, "Effects of Psychoactive Drugs on Conditioned Avoidance Response in Mongolian Gerbils (Meriones unguiculatus): Comparison with Wistar Rats and dd Mice,” Pharmacology Biochemistry and Behavior, Vol. 23, No. 6, 1985, pp. 1013-1018. doi:10.1016/0091-3057(85)90108-X

[24] T. Umezu, H. Kuribara and S. Tadokoro, “Acquisition Process and Effects of Psychoactive Drugs on Discrete Shuttle Avoidance Response in Mongolian Gerbils 
(Meriones unguiculatus)," Japanese Journal of Pharmacology, Vol. 47, No. 3, 1988, pp. 245-252. doi:10.1254/jip.47.245

[25] T. Umezu, H. Kuribara, K. Hirate, T. Saito and S. Tadokoro, “A Brief Brain Ischemia Produces Morphological Damage of Hippocampal CA1 Pyramidal Cells without Affecting the Sensitivities to Psychoactive Drugs in Two Types of Discrete Avoidance Tasks in Mongolian Gerbils,” Japanese Journal of Pharmacology, Vol. 50, No. 1, 1989, pp. 63-69. doi:10.1254/jip.50.63

[26] T. Umezu, "Evaluation of the Effects of Plant-Derived Essential Oils on Central Nervous System Function Using Discrete Shuttle-Type Conditioned Avoidance Response in Mice,” Phytotherapy Research, Vol. 26, No. 6, 2012, pp. 884-891. doi:10.1002/ptr.3665

[27] H. Kuribara and S. Tadokoro, "Development of Tolerance to Ambulation-Increasing Effect of Scopolamine Dependent on Environmental Factors in Mice," Japanese Journal of Pharmacology, Vol. 33, No. 5, 1983, pp. 1041-1048. doi:10.1254/jjp.33.1041

[28] T. Asami, H. Kuribara and S. Tadokoro, "Effects of Repeated Administration of Bromocryptine on Ambulatory Activity in Mice," Japanese Journal of Psychopharmacology, Vol. 6, No. 3, 1986, pp. 309-317.

[29] H. Kuribara and S. Tadokoro, "Circadian Variation in the Ambulation-Increasing Effect of Apomorphine after Repeated Administration in Mice," Japanese Journal of Psychopharmacology, Vol.4, No. 3, 1984, pp. 231-236.

[30] H. Kuribara, T. Asami, I. Ida and S. Tadokoro, "Characteristics of the Ambulation-Increasing Effect of the NonCompetitive NMDA Antagonist MK-801 in Mice: Assessment by the Coadministration with Central-Acting drugs," Japanese Journal of Pharmacology, Vol. 50, No. 1, 1992, pp. 11-18. doi:10.1254/jip.58.11

[31] H. Kuribara and Y. Uchihashi, "Dopamine Antagonists Can Inhibit Methamphetamine Sensitization, but Not Cocaine Sensitization, when Assessed by Ambulatory Activity in Mice," Journal of Pharmacy and Pharmacology, Vol. 45, No.12, 1993, pp. 1042-1045. doi:10.1111/j.2042-7158.1993.tb07177.x

[32] H. Kuribara, "Dopamine D1 and D2 Receptor Antagonists Suppress Acute Stimulant Action of Cocaine, but Enhance Cocaine Sensitization," Japanese Journal of Psychiatry and Neurology, Vol. 48, No. 4, 1994, pp. 907911.

[33] H. Kuribara, "Caffeine Enhances the Stimulant Effect of Methamphetamine, but May Not Affect Induction of Methamphetamine Sensitization of Ambulation in Mice," Psychopharmacology, Vol. 116, No. 2, 1994, pp. 125-129. doi:10.1007/BF02245053

[34] H. Kuribara, "Modification of Morphine Sensitization by Opioid and Dopamine Receptor Antagonists: Evaluation by Studying Ambulation in Mice," European Journal of Pharmacology, Vol. 275, No. 3, 1995, pp. 251-258. doi:10.1016/0014-2999(94)00787-8

[35] H. Kuribara, "Inhibition of Methamphetamine Sensitization by Post-Methamphetamine Treatment with SCH 23390 or Haloperidol,” Psychopharmacology, Vol. 119, No. 1, 1995, pp. 34-38. doi:10.1007/BF02246051
[36] T. Umezu, J. Yonemoto, Y. Soma and T. Suzuki, “Tris(2chloroethyl)phosphate Increases Ambulatory Activity in Mice. Pharmacological Analyses of Its Neurochemical Mechanism,” Toxicology and Applied Pharmacology, Vol. 148, No. 1, 1998, pp. 109-116. doi:10.1006/taap.1997.8312

[37] T. Umezu, K. Nakamiya, K. Kita, T. Ochi, Y. Shibata and M. Morita, "Diphenylarsinic Acid Produces Behavioral Effects in Mice Relevant to Symptoms Observed in Citizens who Ingested Well Water," Neurotoxicology and Teratology, Vol. 34, No. 1, 2012, pp. 143-151. doi:10.1016/j.ntt.2011.08.007

[38] T. Umezu, "Unusual Effects of Nicotine as a Psychostimulant on Ambulatory Activity in Mice," ISRN Pharmacology, Vol. 2012, 2012, Article ID: 170981. doi:10.5402/2012/170981

[39] C. T. Dourish, "A Pharmacological Analysis of the Hyperactivity Syndrome Induced by Beta-Phenylethylamine in the Mouse,” British Journal of Pharmacology, Vol. 77, No. 1, 1982, pp. 129-139. doi:10.1111/j.1476-5381.1982.tb09278.x

[40] R. Redolat, J. Vidal, M. C. Gomez and M. C. Carrasco, "Effects of Acute Bupropion Administration on Locomotor Activity in Adolescent and Adult Mice,” Behavioural Pharmacology, Vol. 16, No. 1, 2005, pp. 59-62. doi:10.1097/00008877-200502000-00007

[41] T. E. Wooters, M. T. Bardo, L. P. Dwoskin, N. M. Midde, A. M. Gomez, C. F. Mactutus, R. M. Booze and J. Zhu, "Effect of Environmental Enrichment on Methylphenidate-Induced Locomotion and Dopamine Transporter Dynamics,” Behavioural Brain Research, Vol. 219, No. 1, 2011, pp. 98-107. doi:10.1016/j.bbr.2011.01.001

[42] W. Koek and F. C. Colpaert, "Inhibition of Methylphenidate-Induced Behaviors in Rats-Differences among Neuroleptics,” Journal of Pharmacology and Experimental Therapeutics, Vol. 267, No. 1, 1993, pp. 181-91.

[43] A. Kuzmin, B. Johansson, L. Gimenez, S. O. Ogren and B. B. Fredholm, "Combination of Adenosine A(1) and A(2A) Receptor Blocking Agents Induces Caffeine-Like Locomotor Stimulation in Mice," European Neuropsychopharmacology, Vol. 16, No. 2, 2006. pp. 129-136. doi:10.1016/j.euroneuro.2005.07.001

[44] S. R. Laviolette, R. P. M. Priebe and J. S. Yeomans, "Role of the Laterodorsal Tegmental Nucleus in Scopolamine- and Amphetamine-Induced Locomotion and Stereotypy," Pharmacology Biochemistry and Behavior, Vol. 65, No. 1, 2000, pp. 163-174. doi:10.1016/S0091-3057(99)00195-1

[45] Q. Zhang, Y. P. Yu, Y. L. Ye, J. T. Zhang, W. P. Zhang and E. Q. Wei, "Spatiotemporal Properties of Locomotor Activity after Administration of Central Nervous Stimulants and Sedatives in Mice,” Pharmacology Biochemistry and Behavior, Vol. 97, No. 3, 2011, pp. 577-855. doi:10.1016/j.pbb.2010.09.011

[46] F. R. C. Dias, L. W. de Matos, M. D. D. Sampaio, R. J. Carey and M. P. Carrera, "Opposite Effects of Low versus High Dose Haloperidol Treatments on Spontaneous and Apomorphine Induced Motor Behavior: Evidence that at a Very Low Dose Haloperidol Acts as an Indirect 
170 Evaluation of Central Nervous System Acting Effects of Plant-Derived Essential Oils Using Ambulatory Activity in Mice

Dopamine Agonist,” Behavioural Brain Research, Vol. 229, No. 1, 2012, pp. 153-159. doi:10.1016/j.bbr.2011.12.042

[47] J. Arnt, "Differential-Effects of Classical and Newer Antipsychotics on the Hypermotility Induced by 2 Dose Levels of d-Amphetamine," European Journal of Pharmacology, Vol. 283, No. 1-3, 1995, pp. 55-62. doi:10.1016/0014-2999(95)00292-S

[48] A. L. Chausmer and J. L. Katz, "The Role of D-2-Like Dopamine Receptors in the Locomotor Stimulant Effects of Cocaine in Mice,” Psychopharmacology, Vol. 155, No. 1, 2001, pp. 69-77. doi:10.1007/s002130000668

[49] H. Kuribara, "Potentiation of the Ambulation-Increasing Effect Induced by Combined Administration of MK-801 with Ethanol in Mice,” Psychopharmacology, Vol. 113, No. 3-4, 1994, pp. 453-456. doi:10.1007/BF02245222

[50] T. Umezu, "Effects of Psychoactive Drugs in the Vogel Conflict Test in Mice,” Japanese Journal of Pharmacology, Vol. 80, No. 2, 1999, pp. 111-118. doi:10.1254/jjp.80.111 